\title{
Influence of Negative-Pressure Wound Therapy on Tissue Oxygenation of the Foot
}

\author{
Yoo-Seok Shon ${ }^{1}$, Ye-Na Lee ${ }^{2}$, Seong-Ho Jeong ${ }^{1}$, Eun-Sang Dhong ${ }^{1}$, Seung-Kyu Han ${ }^{1}$ \\ Departments of ${ }^{1}$ Plastic Surgery and ${ }^{2}$ Nursing Service, Korea University Guro Hospital, Korea University College of Medicine, Seoul, Korea
}

Background Negative-pressure wound therapy (NPWT) is believed to accelerate wound healing by altering wound microvascular blood flow. Although many studies using laser Doppler have found that NPWT increases perfusion, recent work using other modalities has demonstrated that perfusion is reduced. The purpose of this study was to investigate the influence of NPWT on tissue oxygenation of the foot, which is the most sensitive region of the body to ischemia.

Methods Transcutaneous partial pressure of oxygen $\left(\mathrm{TcpO}_{2}\right)$ was used to determine perfusion beneath NPWT dressings of 10 healthy feet. The sensor was placed on the tarso-metatarsal area of the foot and the NPWT dressing was placed above the sensor. $\mathrm{TcpO}_{2}$ was measured until it reached a steady plateau state. The readings obtained at the suction-on period were compared with the initial baseline (pre-suction) readings.

Results $\mathrm{TcpO}_{2}$ decreased significantly immediately after applying NPWT, but gradually increased over time until reaching a steady plateau state. The decrease in $\mathrm{Tcp}_{2}$ from baseline to the steady state was 2.9 to $13.9 \mathrm{~mm} \mathrm{Hg}$ (mean, $9.3 \pm 3.6 \mathrm{~mm} \mathrm{Hg} ; 13.5 \pm 5.8 \%$; $\mathrm{P}<0.01$ ). All feet reached a plateau within 20 to 65 minutes after suction was applied.

Conclusions NPWT significantly decrease tissue oxygenation of the foot by 2.9 to $13.9 \mathrm{~mm} \mathrm{Hg}$. NPWT should be used with caution on feet that do not have adequate tissue oxygenation for wound healing.

Keywords Negative-pressure wound therapy / Oxygen partial pressure determination, Transcutaneous / Foot
Correspondence: Seung-Kyu Han Department of Plastic Surgery, Korea University Guro Hospital, Korea University College of Medicine, 148 Gurodong-ro, Guro-gu, Seoul 152-703, Korea Tel: +82-2-2626-3333 Fax: +82-2-868-6698 E-mail: pshan@kumc.or.kr

This article was presented at the 71th Congress of Korean Society of Plastic and Reconstructive Surgeons on November 1-3, 2013 in Seoul, Korea.

No potential conflict of interest relevant to this article was reported.

Received: 30 May 2014 • Revised: 21 Jun 2014 • Accepted: 26 Jun 2014

pISSN: 2234-6163 • elSSN: 2234-6171 • http://dx.doi.org/10.5999/aps.2014.41.6.668 • Arch Plast Surg 2014;41:668-672

\section{INTRODUCTION}

Negative-pressure wound therapy (NPWT) is a mode of therapy used to encourage wound healing. It is used both as primary treatment of chronic and complex wounds and as an adjunct treatment for temporary closure and wound preparation preceding surgical procedures such as skin grafts and flap surgery $[1,2]$. This therapy has been widely and successfully used, al- though the physiologic basis of its effects is not yet fully understood. Numerous controversies exist regarding the mechanism of action, especially with regards to tissue perfusion. It is generally believed that increased blood flow induced by negative pressure plays a beneficial role and several studies have measured increased regional blood flow under negative pressure [2-5].

However, these studies had several limitations. First, almost all studies evaluating perfusion changes due to NPWT have used 
laser Doppler and the use of laser Doppler may be inappropriate in this setting. Laser Doppler measures perfusion by multiplying the velocity and concentration of red blood cells [5-8]. During NPWT, the velocity of blood flow beneath the dressing increases in as the vessels become compressed and narrow. Consequently, laser Doppler can incorrectly record increased perfusion due to tissue compression [9]. Recently, some studies have measured tissue perfusion using other modalities, and have reported decreased perfusion during NPWT. Another potential problem is the site at which perfusion is measured. Previous studies have measured perfusion near the NPWT dressing, on normal skin adjacent to the wound edge, not beneath the dressing. Although increased perfusion was measured at the wound edge, this does not guarantee that there is increased blood flow in the wound bed. Indeed, recent studies that have measured perfusion beneath the NPWT dressing, have obtained contrasting results $[10,11]$.

The need to assess perfusion using an alternative modality at the right location is apparent. In this study, we evaluated perfusion beneath NPWT dressings by using transcutaneous partial pressure of oxygen $\left(\mathrm{TcpO}_{2}\right)$. TcpO $\mathrm{O}_{2}$ has been recommended as a sensitive method for assessing dermal oxygen supply in a defined cutaneous area [12]. It has been used over the past decade to accurately assess the potential of wound healing [12].

\section{METHODS}

The study was conducted in a room with a set temperature of $22^{\circ} \mathrm{C}$ to $24^{\circ} \mathrm{C}$. Ten vacuum assisted closure (VAC) dressings (Ki- netic Concepts, Inc. [KCI], San antonio, TX, USA) and polyurethane foam dressings (GranuFoam Small Dressing, 10 × 7.5 $\times 3.2$ $\mathrm{cm}$; KCI) were placed on the foot of 10 healthy volunteers. The mean age of the volunteers was 29 years (range, 24-32 years). There were 6 men and 4 women. None of the volunteers had a history of diabetes mellitus or vasculopathy. A TcpO $\mathrm{O}_{2}$ (PeriFlux System 5000, Perimed, Stockholm, Sweden) that measures the tissue oxygen tension was used to assess perfusion. The sensor of $\mathrm{TcpO}_{2}$ was fixed onto the tarso-metatarsal area of the foot in the first intermetatarsal space with double-sided adhesive rings and contact liquid with the transducer heated to $44^{\circ} \mathrm{C}$.

On one area of the foam dressing, a portion was cut out to fit the shape and size of the $\mathrm{TcpO}_{2}$ sensor. The prepared foam dressing was then applied above the sensor so that the cut-out portion fit over the sensor. The overlying foam dressing was carefully sealed with an adhesive transparent film so as not to affect the baseline $\mathrm{TcpO}_{2}$ value by compressing the foam dressing. After confirming that the foam dressing did not change the $\mathrm{TcpO}_{2}$, a drainage tube was connected to the foam dressing on the opposite side of the $\mathrm{TcpO}_{2}$ sensor location to avoid direct compression of the sensor. This can minimize additional pressure at the sensor site while a vacuum pump delivers pressure. Suction pressure of $125 \mathrm{~mm} \mathrm{Hg}$ was then applied until $\mathrm{TcpO}_{2}$ reached a steady plateau state. The patients were lying comfortably on their backs throughout the measurement (Fig. 1).

The $\mathrm{TcpO}_{2}$ levels during NPWT were compared with those at baseline (before NPWT). This study was approved by the Institutional Review Board of the authors' institution. All participants gave informed consent.

\section{Fig. 1. NPWT dressing above the $\mathrm{TcpO}_{2}$ sensor}

NPWT with the $\mathrm{TcpO}_{2}$ sensor beneath the foam dressing. (A) $\mathrm{TcpO}_{2}$ sensor placed on the tarso-metatarsal area. (B) On one area of the foam dressing, a portion was cut out to fit the shape and size of the $\mathrm{TcpO}_{2}$ sensor. (C) The foam dressing was applied above the sensor. A drainage tube was connected to the foam dressing on the opposite side of the $\mathrm{TcpO}_{2}$ sensor location. Negative pressure was applied. NPWT, negative-pressure wound therapy; $\mathrm{TcpO}_{2}$, transcutaneous partial pressure of oxygen.
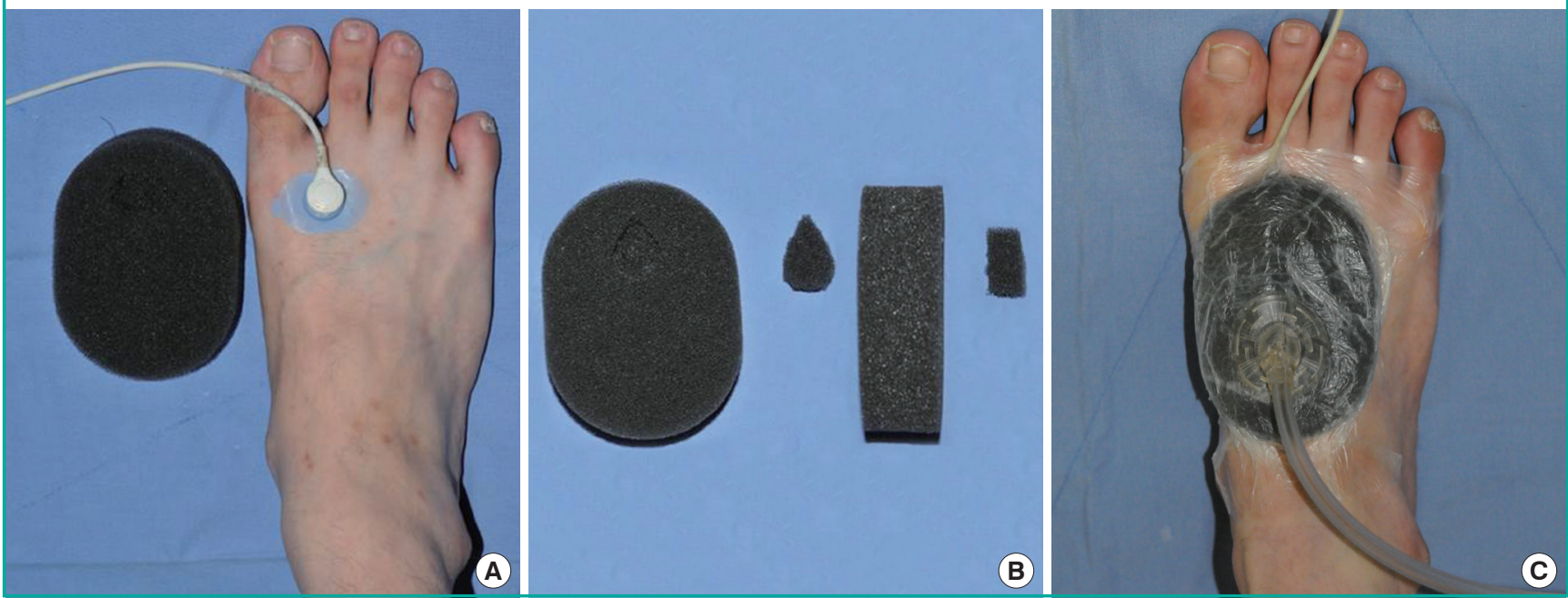
Table 1. Reduction in transcutaneous partial pressure of oxygen for each foot undergoing NPWT $(n=10)$

\begin{tabular}{|c|c|c|c|c|c|}
\hline Volunteer & Sex/Age (yr) & Initial baseline $(\mathrm{mm} \mathrm{Hg})$ & Final plateau (mm Hg) & Difference $(\%)$ & Time to reach a plateau ( $\mathrm{min}$ ) \\
\hline 1 & Male/30 & 70.2 & 62.4 & $7.8(11.1)$ & 65 \\
\hline 2 & Male/28 & 76.7 & 66.2 & $10.5(13.6)$ & 55 \\
\hline 3 & Female/30 & 56.4 & 44.6 & $11.8(17.8)$ & 50 \\
\hline 4 & Male/27 & 80.0 & 77.1 & $2.9(3.6)$ & 30 \\
\hline 5 & Male/30 & 64.9 & 56.4 & $8.5(13.1)$ & 45 \\
\hline 6 & Female/32 & 78.3 & 66.3 & $12.0(15.3)$ & 20 \\
\hline 7 & Female/29 & 57.8 & 43.9 & $13.9(24.0)$ & 35 \\
\hline 8 & Male/29 & 66.5 & 60.8 & $5.7(8.6)$ & 25 \\
\hline 9 & Male/31 & 70.3 & 63.7 & $6.6(9.3)$ & 25 \\
\hline 10 & Female/24 & 72.6 & 59.1 & $13.5(18.6)$ & 50 \\
\hline Mean \pm SD & - & $69.3 \pm 8.1$ & $60.0 \pm 10.0$ & $9.3 \pm 3.6(13.5 \pm 5.8)$ & $40 \pm 15.1$ \\
\hline
\end{tabular}

\section{Fig. 2. $\mathrm{TcpO}_{2}$ change after applying NPWT}

Typical example of $\mathrm{TcpO}_{2}$ change illustrating the testing time period. $\mathrm{Tcp}_{2}$ decreased significantly immediately after applying NPWT, but gradually increased over time until reaching a steady plateau state. $\mathrm{TcpO}_{2}$, transcutaneous partial pressure of oxygen; NPWT, negative-pressure wound therapy.

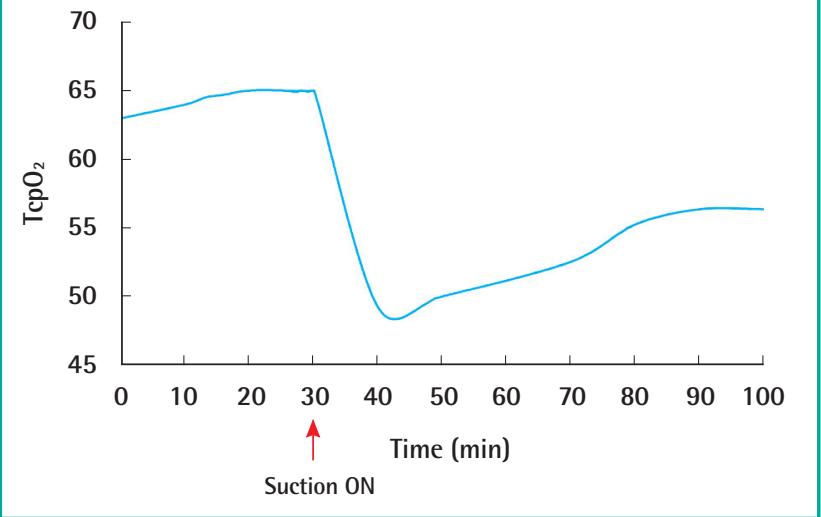

\section{Statistical analysis}

The measurements from each volunteer that underwent NPWT were treated as an independent set of data. Perfusion changes for each individual were analyzed with the Wilcoxon signed rank test. P-values $<0.01$ were considered statistically significant.

\section{RESULTS}

The $\mathrm{TcpO}_{2}$ at baseline was 56.4 to $78.3 \mathrm{~mm} \mathrm{Hg}$ (mean, 69.3 \pm $8.1 \mathrm{~mm} \mathrm{Hg}$ ). During the period when suction was applied, $\mathrm{TcpO}_{2}$ decreased in all 10 feet $(44.6$ to $77.1 \mathrm{~mm} \mathrm{Hg}$ ). The decrease in the $\mathrm{TcpO}_{2}$ between baseline and the steady plateau state was 2.9 to $13.9 \mathrm{~mm} \mathrm{Hg}$ (mean, $9.3 \pm 3.6 \mathrm{~mm} \mathrm{Hg} ; 13.5 \pm$ $5.8 \%$; $\mathrm{P}<0.01$ ) (Table 1).

Fig. 2 illustrates a typical example of one of the tests, demonstrating the various time periods. $\mathrm{TcpO}_{2}$ decreased significantly immediately after applying NPWT, but gradually increased over time until reaching a steady plateau state. All feet reached a plateau within 20 to 65 minutes after suction was applied. During the study, there were no significant complications including pain, erythema, or other skin problems. All volunteers were tolerable throughout the whole study period.

\section{DISCUSSION}

This study demonstrates that tissue perfusion is substantially decreased beneath NPWT dressings. These results are in contrast to previous studies that have used laser Doppler [3-6]. Indeed, the laser Doppler itself may be the confounding factor responsible for the conflicting reports.

Although laser Doppler results are clinically correlated with perfusion, these results are derived by multiplying blood velocity by the concentration of red blood cells [5-8]. The accuracy of this calculation is questionable, however, since NPWT is associated with external compression force [9]. The continuity equation states that a reduction in the diameter of a tube leads to an increase in the velocity of the flow of fluid in the tube. Since the tissues are compressed in NPWT, the diameters of the vessels are reduced. This may increase the velocity of blood flowing through the narrower vessels, thereby resulting in the laser Doppler incorrectly interpreting this as an increase in perfusion.

Furthermore, laser Doppler is very sensitive to movement. When laser Doppler probes are placed beneath the foam of the vacuum dressing, the probe is pushed against the tissues as the foam collapses. This force applied to the tissues not only affects perfusion, but may interfere with laser Doppler readings. Thus, laser Doppler is not an appropriate method for measuring perfusion beneath NPWT dressings.

Instead of using laser Doppler, we evaluated perfusion with the $\mathrm{TcpO}_{2}$. Since the first clinical evaluation of transcutaneous oxygen tension measurement [12], this technique has been recom- 
mended as a reproducible, sensitive, and quantitative method for assessing dermal oxygen supply in a defined cutaneous area [13]. $\mathrm{TcpO}_{2}$ measured on the lower extremity of patients with or without diabetes mellitus has been shown to provide diagnostic and prognostic information for wound healing potential in several clinically important areas.

Similar to our study, Kairinos et al. [11] used $\mathrm{TcpO}_{2}$ to measure the perfusion beneath NPWT dressings. A doughnut-shaped foam dressing was designed to prevent the application of pressure to the $\mathrm{TcpO}_{2}$ sensor. However, to evaluate the influence of negative pressure, every area under the foam dressing, including the sensor, should be compressed by negative pressure. The assessment of $\mathrm{TcpO}_{2}$ represents the extent of oxygen diffusion through the skin, and it should not be affected by external compression. Instead of a doughnut-shaped foam dressing, we made a small hole in the center of the foam to minimize the additional pressure at the location of the sensor.

There are other studies in which modalities other than laser Doppler were used to measure perfusion changes due to NPWT. In the study of Lindstedt et al. [14], coronary artery blood flow was measured with electromagnetic flow meter probes. Chen et al. [15] used a microcirculation microscope to demonstrate perfusion adjacent to wounds created on rabbit ears. Both studies were able to avoid the drawbacks of laser Doppler, but they were unable to measure perfusion directly beneath the NPWT dressing.

Previous investigators have measured blood flow at the normal skin adjacent to the wound edge, not in the wound bed. However, increased perfusion adjacent to the wound edge does not necessarily reflect increased blood flow in the wound bed. Furthermore, the wound bed is the main origin of the vascularity that provides nutrients and oxygen to sustain newly formed granulation tissue [16]. The wound bed offers a site where fibroblasts migrate and proliferate and where active synthesis of the extracellular matrix occurs [17]. Although this study used healthy volunteers, we sought to measure perfusion beneath the dressing where a wound would typically exist.

An animal study has measured perfusion beneath NPWT dressings. Ichioka et al. [10] developed an experimental model capable of visualizing the wound bed microcirculation. In that study, a superficial wound was made on the gluteal region of a mouse, allowing the intact subdermal plexus to be directly visualized with an intravital microscope. Enhanced blood flow in the wound bed was seen at a pressure of $125 \mathrm{~mm} \mathrm{Hg}$. However, the wound was not fully covered by the foam dressing. Instead, a transparent adhesive drape was used to cover the wound. This is not a typical NPWT dressing on a wound, and the compressive force of the dressing would be much less than that of a typical dressing. This may explain the observed increased perfusion in these vessels.

Although NPWT can decrease tissue oxygenation of the foot, this does not imply that NPWT is a harmful treatment. On the contrary, reduced perfusion may possibly be beneficial for a wound. In most wounds, the application of NPWT at a reasonable suction pressure will result in relative ischemia rather than total anoxia. Ischemia is one of the most powerful stimuli for neovascularization. Neovascularization, which is defined as the growth of new blood vessels in response to tissue ischemia, is critical for wound healing, survival of transplanted tissue, and recovery from tissue ischemia [18]. In addition, the increased tissue pressure causing reduced perfusion is also beneficial, because it reduces edema and prevents further formation [19]. Thus, increased tissue pressure and the associated reduction in perfusion are likely to be beneficial to wound healing in many cases.

A limitation of this study is that each experiment was carried out over a period of a few hours. Although the time period over which perfusion was observed is longer than in previous studies, it still may not reflect perfusion changes over a longer period. Another limitation of this study is that it was performed on intact skin rather than open wounds. As a pilot study, the volunteers were all healthy without a history of peripheral vasculopathy. The minimal $\mathrm{TcpO}_{2}$ value thought to be required for adequate wound healing in diabetic wounds is 20 to $40 \mathrm{~mm} \mathrm{Hg}$ [20]. In this study, every $\mathrm{TcpO}_{2}$ of the foot was higher than 56 $\mathrm{mm} \mathrm{Hg}$, and these values did not decrease below $40 \mathrm{~mm} \mathrm{Hg}$ after negative pressure was applied. Perfusion may decrease more on poorly perfused tissues like diabetic feet with vasculopathy, although this has not been studied. Nonetheless, we suggest that NPWT be applied with caution in these patients.

As a conclusion, NPWT can significantly decrease the tissue oxygenation of the foot. This study raises concerns regarding the role of NPWT in tissues with compromised perfusion. Since perfusion was reduced with NPWT in this study, these dressings should be applied with caution on poorly perfused tissues.

\section{REFERENCES}

1. Argenta LC, Morykwas MJ, Marks MW, et al. Vacuum-assisted closure: state of clinic art. Plast Reconstr Surg 2006; 117:127S-142S.

2. Banwell P, Teot L. Topical negative pressure (TNP): the evolution of a novel wound therapy. J Tissue Viability 2006; $16: 16-24$.

3. Morykwas MJ, Simpson J, Punger K, et al. Vacuum-assisted closure: state of basic research and physiologic foundation. Plast Reconstr Surg 2006;117:121S-126S. 
4. Timmers MS, Le Cessie S, Banwell P, et al. The effects of varying degrees of pressure delivered by negative-pressure wound therapy on skin perfusion. Ann Plast Surg 2005;55: 665-71.

5. Wackenfors A, Gustafsson R, Sjogren J, et al. Blood flow responses in the peristernal thoracic wall during vacuum-assisted closure therapy. Ann Thorac Surg 2005;79:1724-30.

6. Wackenfors A, Sjogren J, Gustafsson R, et al. Effects of vacuum-assisted closure therapy on inguinal wound edge microvascular blood flow. Wound Repair Regen 2004;12:600-6.

7. Basic theory and operating principles of laser Doppler blood flow monitoring and imaging (LDF \& LDI), issue 1 [Internet]. Devon; Moor Instruments; 2014 [2014 Jul 1]. Available from: http://www.moor.co.uk/ckfinder/userfiles/ files/Moor_Laser_doppler_theory_Issue_1.pdf.

8. Detre JA, Ances BM, Takahashi K, et al. Signal averaged laser Doppler measurements of activation-flow coupling in the rat forepaw somatosensory cortex. Brain Res 1998;796: 91-8.

9. Morales F. Improving the clinical applicability of laser Doppler perfusion monitoring. Enschede: Print Partners Ipskamp; 2005.

10. Ichioka S, Watanabe $\mathrm{H}$, Sekiya $\mathrm{N}$, et al. A technique to visualize wound bed microcirculation and the acute effect of negative pressure. Wound Repair Regen 2008; 16:460-5.

11. Kairinos N, Voogd AM, Botha PH, et al. Negative-pressure wound therapy II: negative-pressure wound therapy and increased perfusion. Just an illusion? Plast Reconstr Surg 2009; 123:601-12.

12. Franzeck UK, Talke P, Bernstein EF, et al. Transcutaneous
PO2 measurements in health and peripheral arterial occlusive disease. Surgery 1982;91:156-63.

13. Rooke TW, Osmundson PJ. Variability and reproducibility of transcutaneous oxygen tension measurements in the assessment of peripheral vascular disease. Angiology 1989;40: 695-700.

14. Lindstedt S, Malmsjo M, Gesslein B, et al. Topical negative pressure effects on coronary blood flow in a sternal wound model. Int Wound J 2008;5:503-9.

15. Chen SZ, Li J, Li XY, et al. Effects of vacuum-assisted closure on wound microcirculation: an experimental study. Asian J Surg 2005;28:211-7.

16. Schultz GS, Sibbald RG, Falanga V, et al. Wound bed preparation: a systematic approach to wound management. Wound Repair Regen 2003;11 Suppl 1:S1-28.

17. Shai A, Maibach HI. Natural course of wound repair versus impaired healing in chronic skin ulcers. In: Shai A, Maibach HI, editors. Wound healing and ulcers of the skin: diagnosis and therapy-the practical approach. Berlin: Springer; 2005. p.7-17.

18. Glotzbach JP, Levi B, Wong VW, et al. The basic science of vascular biology: implications for the practicing surgeon. Plast Reconstr Surg 2010;126:1528-38.

19. Kairinos N, Solomons M, Hudson DA. Negative-pressure wound therapy I: the paradox of negative-pressure wound therapy. Plast Reconstr Surg 2009; 123:589-98.

20. Jang SY, Jeong TW, Han SK, et al. Transcutaneous oxygen pressure to predict wound healing in mild diabetic feet. J Korean Soc Plast Reconstr Surg 2011;38:585-9. 